\title{
The contemporary role of metastasectomy in the management of metastatic RCC
}

\author{
Zachary Feuer, Jacob I. Taylor, William C. Huang \\ Department of Urology, New York University Langone Health, New York, NY 10016, USA.
}

Correspondence to: Dr. William C. Huang, Department of Urology, New York University Langone Health, New York, NY 10016, USA. E-mail:William.huang@nyulangone.org

How to cite this article: Feuer Z, Taylor Jl, Huang WC. The contemporary role of metastasectomy in the management of metastatic RCC. J Cancer Metastasis Treat 2021;7:68. https://dx.doi.org/10.20517/2394-4722.2021.164

Received: 14 Aug 2021 First Decision: 29 Sep 2021 Revised: 29 Sep 2021 Accepted: 26 Oct 2021 Published: 5 Dec 2021

Academic Editor: Hendrik Van Poppel Copy Editor: Xi-Jun Chen Production Editor: Xi-Jun Chen

\begin{abstract}
Metastasectomy was initially described in the 1970s as a therapeutic strategy for patients with metastatic renal cell carcinoma. Since that time, systemic therapy options have grown exponentially, most recently with the introduction of immunotherapy. We aimed to review the contemporary literature regarding the role of metastasectomy in the era of targeted therapy and immunotherapy. Historically, metastasectomy has benefited patients with small volume, single-organ metastases, with favorable outcomes amongst younger, healthier patients with metastases to specific sites. The interplay between the employment of metastasectomy and systemic therapy has been limited to small, retrospective series with significant patient selection bias. More recently, investigators have conducted randomized controlled trials exploring the use of targeted therapies in the adjuvant setting after metastasectomy. Initial randomized data suggested no benefit in using sorafenib in this setting, and a subsequent study demonstrated possible harm in using pazopanib after metastasectomy. However, the role of other novel systemic therapies, including immunotherapy, nor the timing of use, have been meaningfully explored. Metastasectomy appears to be a valuable therapeutic option in the properly selected patient, requiring a multidisciplinary management strategy and, pending future trials, a multimodal treatment approach.
\end{abstract}

Keywords: Clear-cell metastatic renal cell carcinoma, metastasectomy, immunotherapy 


\section{INTRODUCTION}

Nearly $30 \%$ of patients with renal cell carcinoma (RCC) have metastatic disease at the time of diagnosis ${ }^{[1]}$. Amongst men treated for localized RCC, approximately $25 \%$ progress in developing metastatic disease ${ }^{[2]}$. Metastases commonly present in the lung (60\%-75\%), lymph nodes (60\%-65\%), bone (39\%-40\%), liver (19\%$40 \%)$ and brain (5\%-7\% $)^{[3]}$. Presently, treatment options for metastatic RCC (mRCC) include observation, clinical trial enrollment, systemic therapy, and metastasectomy (with or without SBRT and/or ablative techniques). There are no recommendations regarding which of these modalities is preferred ${ }^{[3]}$.

With the rapid evolution of systemic therapy options in the era of targeted therapies and immuno-oncology, level I evidence for the role of surgery in metastatic disease, and specifically metastasectomy, remains sparse. This is due to study limitations associated with patient performance status, disease distribution, and the surgical accessibility of metastatic sites, all of which are associated with significant selection bias ${ }^{[4]}$. Nevertheless, metastasectomy remains a recommended management option for mRCC in select patients ${ }^{[5]}$.

We aim to review the literature pertaining to the historical role of metastasectomy, including a discussion of outcomes-based upon metastatic site, and determine the role of metastasectomy in the era of immunotherapy.

\section{THE EARLY ROLE OF METASTASECTOMY}

The role of metastasectomy has evolved over the past several decades as the landscape of treatments for mRCC has transitioned from the cytokine era to targeted therapies and immuno-oncology, as well as combinations of these therapies. The first large, retrospective series to examine the role of metastasectomy in the cytokine era was conducted in 278 patients and demonstrated that solitary metastasis, longer diseasefree interval (DFI), and younger age were associated with extended survival. In this study, 5-year survival was approximately $55 \%{ }^{[6]}$. A subsequent study retrospectively evaluated 152 resections in 101 patients. Disease-free survival was noted to be low, $\sim 7 \%$, at 60 months, but resection was determined to be feasible with low morbidity. Overall survival was not assessed ${ }^{[7]}$.

Another retrospective analysis, conducted by Alt et al. ${ }^{[8]}$ during the cytokine era, assessed 887 patients who underwent nephrectomy for RCC and subsequently developed metastases. After controlling for patient performance status, timing, location, and the number of metastases, they found that complete metastasectomy was associated with prolongation of cancer-specific survival (4.8 years vs. 1.3 years). In patients with lung-only metastases, 5-year cancer-specific survival was $73.6 \%$ with complete resection $v s$. $19 \%$ amongst patients who were managed non-operatively ${ }^{[8]}$. These early studies demonstrated that in the absence of effective systemic therapy, complete metastasectomy was an effective treatment strategy for patients with mRCC.

\section{IMAGING IN METASTATIC RENAL CELL CARCINOMA STAGING}

The primary imaging techniques for the initial staging of a primary renal mass include computerized tomography (CT) and magnetic resonance imaging (MRI). Generally, CT is utilized as the primary modality, conserving MRI for situations in which iodinated contrast is contraindicated or when further soft tissue delineation is necessary for accurate staging ${ }^{[0]}$. The National Comprehensive Cancer Network recommends that chest imaging be obtained with a chest radiograph (CXR). Meanwhile, these guidelines suggest that CT of the chest, CT of the brain, and/or a bone scan are obtained if clinically indicated ${ }^{[3]}$. However, the American College of Radiology Appropriateness Criteria recommends obtaining CT of the chest for stage $\geq \mathrm{T} 2$ tumors, as small pulmonary metastases may be missed on $\mathrm{CXR}^{[10]}$. 
Nuclear medicine may play a role in mRCC diagnosis and staging. Positron emission tomography $(\mathrm{PET}) / \mathrm{CT}$ represents a modality that may provide better sensitivity for the diagnosis of metastases ${ }^{[11]}$. Fluorine 18-sodium fluoride ligand has been demonstrated to be sensitive for the detection of bone metastases ${ }^{[10]}$. More recently, PET/CT using Zr-89-girentuximab, a monoclonal antibody-based ligand, was demonstrated to be more sensitive than CT alone, than F-fluorodeoxyglucose (18F)-PET/CT for detecting bone and soft tissue lesions in patients with good and intermediate-risk mRCC ${ }^{[12]}$.

\section{THE ROLE OF METASTASECTOMY IN SPECIFIC ORGAN SITES}

The role of metastasectomy has been reviewed extensively in the literature, often in series assessing the role of metastasectomy by specific organ site. Metastasectomy outcomes by organ site are summarized in Table 1.

\section{Lung}

The role of metastasectomy in the management of pulmonary metastases in the setting of mRCC has been well-characterized. Pfannschmidt et al. ${ }^{[13]}$ retrospectively assessed pulmonary metastasectomy in 191 patients, including patients with no primary tumor site recurrence and no extrapulmonary metastases. Complete resection was achieved in 145 cases. This study demonstrated an overall 5-year survival of $36.9 \%$, $41.5 \%$ in patients who underwent complete resection $v$ s. $22.1 \%$ amongst those with partial resections. The authors dichotomized prognostic indicators based on values that demonstrated the most significant discrimination between good and poor outcomes. They noted a significant survival difference amongst patients with $<7$ metastases as compared to $\geq 7$ individual sites $(46.8 \% v$ s. $14.5 \%)$. Finally, they noted that DFI greater than 23 months was associated with an improvement in 5 -year survival $(47 \% \text { vs. } 24.7 \%)^{[13]}$.

A German study analyzed the impact of the histologic characteristics of the primary tumor on survival in 107 consecutive patients undergoing pulmonary metastasectomy. Complete resections were performed in 97.2\% of patients, and $33.6 \%$ received systemic therapy prior to pulmonary metastasectomy. The mean survival was 63.4 months with 5- and 10-year survival rates of $47 \%$ and $9 \%$, respectively. The authors found that node status, primary tumor histologic grade, and primary tumor stage were all associated with worse survival outcomes despite metastasectomy. The effect of systemic therapy was not evaluated. ${ }^{[14]}$

Kudelin et al. ${ }^{[15]}$ reviewed 116 patients who underwent pulmonary metastasectomy with intrathoracic lymph node dissection. In this cohort, $34.5 \%$ of patients had systemic therapy prior to metastasectomy. Five- and ten-year survival was noted to be $49 \%$ and $21 \%$, respectively. Age $>70$, female gender and the number of metastases were noted to be poor prognostic factors. Only age $>70$ remained significant in multivariate analysis $^{[15]}$.

More recently, Saricam et al. ${ }^{[16]}$ evaluated the role of pulmonary metastasectomy in 48 patients, demonstrating a median survival of 56.2 months, with a 5 -year survival of $62.5 \%$. The study noted that DFI $>32$ months, fewer, and smaller volume metastases $\left(<4 \mathrm{cc}^{3}\right)$ were factors associated with better prognosis ${ }^{[16]}$.

\section{Bone}

Bone metastases are present in approximately $40 \%$ of patients with $\operatorname{mRCC}^{[3]}$. To assess prognostic indicators, Kume et al. ${ }^{[17]}$ reviewed 94 patients with bone metastases at multiple tertiary referral centers. The authors noted that sarcomatoid differentiation, vertebral bone involvement, concurrent non-bone metastases, alkaline phosphatase increases $>1.5$ times the upper limit of normal, and C-reactive protein increases $>0.3 \mathrm{mg} / \mathrm{dL}$ were associated with poor prognosis ${ }^{[17]}$. 
Table 1. Summary of metastasectomy outcomes by metastatic site

\begin{tabular}{|c|c|c|c|}
\hline Site & 5-year OS & Favorable features & Unfavorable features \\
\hline Lung $^{[13-17]}$ & $39.9 \%-62.5 \%$ & $\begin{array}{l}\cdot \text { DFI }>23 \text { months } \\
\cdot<3 \text { metastases } \\
\cdot \text { Small volume metastases }(<4 \mathrm{cc})\end{array}$ & $\begin{array}{l}\cdot \text { - Age }>70 \\
\cdot \text { Higher primary tumor stage/grade }\end{array}$ \\
\hline Bone $^{[18-25]}$ & $11 \%-48 \%$ & $\begin{array}{l}\text { - Solitary metastases } \\
\text { - Bone-only metastases } \\
\text { - Clear-cell histology }\end{array}$ & $\begin{array}{l}\text { - Sarcomatoid differentiation } \\
\text { - Concurrent non-bone metastases } \\
\text { - Alkaline phosphatase }>1.5 \times \text { the upper limit of normal } \\
\text { - CRP increase by }>0.3 \mathrm{mg} / \mathrm{dL} \\
\text { - Pelvic metastases }\end{array}$ \\
\hline Liver $^{[26-29]}$ & $43 \%-62 \%(29 \% 2 \text {-year OS })^{[29]}$ & $\begin{array}{l}\text { - Metachronous metastases } \\
\text { - *Solitary metastases }\end{array}$ & $\begin{array}{l}\text { - Synchronous metastases } \\
\text { - Eastern Cooperative Oncology Group score >0 } \\
\text { - High-grade histopathology }\end{array}$ \\
\hline $\operatorname{Brain}^{[30]}$ & $8.5 \%$ & -NA & -NA \\
\hline
\end{tabular}

*Noted to be beneficial in one study, no benefit in another. DFI: Disease free interval; CRP: C-reactive protein; OS: overall survival; NA: not applicable.

A recent descriptive study demonstrated that men were four times more likely to harbor bone metastases. Lesions had a predilection for axial bone and the incidence of severe events, including pathologic fracture, was nearly $55 \%$. Shorter time to bone metastasis, older age, multiorgan metastases, and carbonic anhydrase expression loss were associated with poor prognosis. Huang et al.$^{[18]}$ noted a median overall survival of 45 months for patients with favorable risk factors and 32 months for patients who were deemed unfavorable risk.

Kollender et al ${ }^{[19]}$ retrospectively analyzed 45 patients with solitary bone metastases and either intractable pain or impending/current pathologic fracture who underwent surgical intervention. The authors noted significant pain relief and good functional outcomes in approximately $90 \%$ of patients. Overall, half of the patients survived more than 2 years, and $38 \%$ survived more than 3 years ${ }^{[19]}$.

Higuchi et al. ${ }^{[20]}$ evaluated survival in 58 patients who underwent surgical intervention for either solitary or multiple bone metastases at a single institution. Amongst the cohort, metastases were noted in the spine in 33 patients, in the appendicular skeleton in 10 patients, in the pelvis in 8 patients, in the thoracic bones in four patients, and in soft tissue in 3 patients. Forty-six patients underwent metastasectomy, and 12 patients underwent curettage. The authors noted an $89 \%$ overall survival at 1 year, $62 \%$ overall survival at 5 years, and $48 \%$ overall survival at 10 years. The median overall survival for patients undergoing metastasectomy was 127 months, and for curettage was 54 months. Of note, pelvic metastases were associated with shorter median overall survival ${ }^{[20]}$.

A study by Lin et al. ${ }^{[21]}$ retrospectively assessed 295 consecutive patients with bone metastases treated at a single institution. Surgical interventions included curettage, en bloc resection, closed nailing, or amputation. The authors noted an overall survival of $47 \%$ and $11 \%$ at 1 and 5 years, respectively. They reported that patients with solitary metastases had the most favorable outcomes, and that patients with bone-only metastases had a favorable prognosis relative to patients with additional extraosseous metastases. Furthermore, clear-cell histology was associated with an improved prognosis. Notably, 5\% of patients died within 30 days of surgery ${ }^{[21]}$.

Ptashnikov et al. ${ }^{[2]}$ recently conducted a retrospective review of 100 patients with spinal mRCC. Metastasectomy was performed in 39 cases while 61 patients underwent decompression procedures with stabilization-only, analyzing pain, neurologic status, overall and progression-free survival. Of these patients, 
26 had adjuvant targeted therapy (7 of whom had undergone metastasectomy). The study noted improvement in neurologic function and pain relief, while the authors found no improvement in overall survival amongst patients managed with each modality. However, amongst all patients, there was an overall survival benefit for those who received targeted therapy ${ }^{[22]}$.

Stereotactic body radiation therapy (SBRT) has been employed in the management of osseous metastases from RCC, both for the treatment of metastases and for palliation. In a study assessing local control of bone metastases after SBRT or external beam radiation therapy, authors assessed response to 95 bone lesions in 46 patients. They noted significantly improved pain control with SBRT vs. EBRT, $74.9 \%$ vs. 39.9\%, 74.9\%, and $35.7 \%$ experiencing improvement at 12 and 24 months, respectively $(P=0.02)$. The median time to radiolographic failure in both groups was similar $(7 \mathrm{months}){ }^{[23]}$. Jhaveri et al. ${ }^{[24]}$ demonstrated a dosedependent effect of SBRT on the efficacy ( $83 \%$ vs. $73 \%$ ) and durability ( $46 \%$ vs. $12 \%$ symptom recurrence) of pain control for patients receiving $>85$ Gy $v$ s. $<85$ Gy doses.

\section{Liver}

Renal cell carcinoma metastatic to the liver occurs in approximately $20 \%-40 \%$ of patients ${ }^{[3]}$. These metastases are difficult to manage as they typically present concurrently with multiple extrahepatic metastases. Furthermore, only $25 \%$ of patients have solitary liver lesions ${ }^{[25]}$. Ruys et al. ${ }^{[26]}$ reviewed 33 patients who underwent intervention for hepatic metastases, with metastasectomy performed in 29 patients. Overall survival was $79 \%$ and $43 \%$ at 1 and 5 years after resection. The authors noted that prognostic factors for improved survival included metachronous metastases and radical resection. Meanwhile, size, solitary metastases, and the presence of extrahepatic metastases were not associated with an impact on overall survival $^{[26]}$.

Staehler et al. ${ }^{[27]}$ retrospectively compared 48 patients who underwent liver metastasectomy and 20 patients who were denied surgery to evaluate overall survival. In this study, nearly $80 \%$ of patients received adjuvant systemic therapy with interleukin therapy. Overall survival at 5 years was $62 \%$ in the group who underwent resection $v s .29 \%$ in those who were observed. The survival difference was most substantial amongst patients with primary tumor low-grade histology (155 months vs. 29 months) in the metastasectomy and observation cohorts, respectively. Notably, patients with synchronous metastases, ECOG scores $>0$ and patients with high-grade histology did not benefit from surgical intervention ${ }^{[27]}$. Although differences were not statistically significant between cohorts, patients who were denied surgery tended to have higher grade disease and higher volume metastatic burden.

In a recent study, Joyce et al. ${ }^{[28]}$ analyzed 34 cases of hepatic metastasectomy. In 17 patients, hepatic resection was performed for a direct invasion of the liver, while 21 patients underwent simultaneous nephrectomy and hepatic metastasectomy. Four patients had both locally invasive and separate hepatic metastases. Amongst these patients, 2-year cancer-specific survival and overall survival were $40 \%$ and $29 \%$, respectively. In a matched cohort of 68 patients undergoing metastasectomy for mRCC to non-hepatic sites, 2 -year cancer-specific survival and overall survival were $40 \%$ and $28 \%$, respectively ${ }^{[28]}$.

\section{Brain}

The role of surgical metastasectomy of brain metastases in $\mathrm{MRCC}$ remains limited. The surgical approach typically includes either SBRT, whole-brain radiotherapy, or surgical resection. Analyses of the role of surgical resection remain limited to case reports and small series. The largest series analyzing the role of surgical resection for brain metastases in $\mathrm{mRCC}$ retrospectively analyzed 50 patients with metachronous brain metastases after primary treatment. The median overall survival from the time of craniotomy was approximately 13 months, with a 10\% postoperative mortality rate. Twenty-two patients received additional 
whole-brain radiotherapy, while 18 patients did not. Overall survival at 1 and 5 years was $51 \%$ and $8.5 \%$, respectively ${ }^{[29]}$.

\section{Lymph nodes}

Lymph nodes are involved in 60\%-65\% of mRCC cases $^{[3]}$. These are typically identified as synchronous metastases, as local nodal recurrence is rare ${ }^{[30]}$. The initial management of lymph node dissection at the time of nephrectomy was assessed when Blom et al. ${ }^{[31]}$ randomized 732 patients, 1:1, to undergo lymph node dissection at the time of nephrectomy or nephrectomy alone. Lymph node dissection did not improve overall survival ( $\mathrm{HR}=1.02,95 \% \mathrm{CI}$ : 0.80-1.29), local regional progression ( $\mathrm{HR}=0.77,95 \% \mathrm{CI}$ : $0.46-1.28)$ or distant progression $(\mathrm{HR}=1.05,95 \% \mathrm{CI}: 0.73-1.50)^{[31]}$. However, the major criticism of this study was that investigators included many low-risk patients with $\mathrm{T} 1$ and $\mathrm{T} 2$ tumors less likely to harbor nodal metastasis.

The role of lymph node dissection at the time of radical nephrectomy for patients with suspected nodal metastases was studied by Pantuck et al. ${ }^{[32]}$. There was no increase in median survival for patients without preoperative evidence of nodal metastases undergoing lymph node dissection $v s$. those who underwent radical nephrectomy alone. However, there was a survival benefit noted amongst patients with concern for nodal metastases who underwent lymphadenectomy as compared to those that did not. The authors reported a 5-month improvement in median overall survival in this cohort ${ }^{[32]}$. Subsequent studies noted no benefit in patients with preoperatively diagnosed $\mathrm{mRCC}^{[3,3,3]}$. To date, the role of lymph node dissection in high-risk patients has not been prospectively studied ${ }^{[35]}$.

\section{INFLUENCE OF PRIMARY TUMOR HISTOLOGY}

Primary tumor histology has been demonstrated to impact prognosis in patients undergoing metastasectomy significantly. A recent systematic review demonstrated that primary tumor features, including findings of Fuhrman high-grade histology and sarcomatoid features, were associated with worse outcomes ${ }^{[36]}$. Takagi et al. ${ }^{[37]}$ noted similar findings with regard to the presence of sarcomatoid features (HR $=8.89, P=0.028)$, however, found that Fuhrman grade was not independently associated ( $\mathrm{HR}=0.83, P=$ 0.757). Another study by Ishihara et al.$^{[38]}$ found that the risk of death amongst patients with non-clear cell histology was double that of patients with clear cell histology.

The impact of primary tumor histology on outcomes has not been directly explored as a primary outcome, and stratification by cell types has been limited given the proportionally low number of patients with nonclear cell findings. However, given the lack of effective systemic therapies for patients with non-clear cell histology, the role of surgical management should be further explored.

\section{COMPLICATIONS OF METASTASECTOMY}

Despite the potential for successful management of mRCC, metastasectomy carries the risk of surgical complications. Palumbo et al. ${ }^{[39]}$ reviewed 351 patients who underwent metastasectomy, noting a complication rate of $55 \%$, including $22 \%$ pulmonary complications, which were not further defined, and a need for transfusion in $15.7 \%$ of patients. A recent retrospective review of 1102 patients who underwent metastasectomy noted an overall complication rate of $45.7 \%$, with a major complication rate Clavien III-IV of $27.5 \%$. The investigators reported that older age, Charlson-Deyo score $\geq 2$, and resection of hepatic metastases were associated with an increased risk of major complications $(\mathrm{OR}=2.59, P<0.001)$, while resection of pulmonary metastases was associated with a decreased risk $(\mathrm{OR}=0.63, P<0.001)^{[40]}$. Despite these complications, resection of metastases has a range of value and chance for intermediate-term survival depending on metastatic disease site. 


\section{ROLE OF SYSTEMIC THERAPY AND METASTASECTOMY}

Karam et al. ${ }^{[41]}$ were amongst the first to assess the combined role of metastasectomy and systemic therapy in a retrospective analysis of 22 patients with mRCC, all of whom were treated with targeted therapy followed by consolidative metastasectomy. Twenty-one patients were alive at the time of the study at a median follow-up of approximately 2 years, while surgical-associated morbidity was low. Amongst these patients, 11 patients developed a recurrence at a median 42 weeks from the time of metastasectomy, while the other 11 patients had not recurred at a similar median interval. Of note, 9 patients received additional systemic therapy after metastasectomy ${ }^{[4]}$.

The use of neoadjuvant therapy followed by metastasectomy was further studied in 124 patients. In this retrospective review, 75 patients received targeted therapy only, 26 underwent targeted therapy followed by complete metastasectomy, and 23 underwent partial resection. In these patients, only complete resection was associated with improved overall survival $(\mathrm{HR}=0.50)$. Of note, this study is had significant selection bias as there was an uneven distribution of poor-risk patients in the study groups. Nearly $23 \%$ of patients in the targeted therapy group were considered poor-risk, as compared to $3.8 \%$ and $0 \%$ in the complete and partial metastasectomy cohorts. ${ }^{[42]}$

\section{ADJUVANT THERAPY AFTER METASTASECTOMY}

Recently, the first RCT in a metastasectomy cohort randomized patients to sorafenib or observation after undergoing complete resection. Sixty-eight patients were randomized, with approximately $80 \%$ in each group harboring solitary metastases. They included patients who underwent cytoreductive nephrectomy with ECOG $\leq 2$, less than 3 metastases, and predominant clear cell histology. Recurrence-free survival was 37 months in the observation arm and 21 months in the sorafenib arm, with significantly more adverse events in the treatment arm. Procopio et al. ${ }^{[43]}$ concluded that sorafenib after metastasectomy was not recommended.

ECOG 2810 is a double-blind RCT, which sought to demonstrate that pazopanib improved disease-free survival in patients who underwent complete metastasectomy as compared to placebo. The study included 129 patients randomized 1:1 for 52 weeks of therapy, seeking to observe a $42 \%$ improvement in disease-free survival at 3 years. The study did not meet the primary endpoint $(\mathrm{HR}=0.85, P=0.47)$. On the contrary, overall survival favored patients receiving placebo (HR for $\mathrm{OS}=2.65, P=0.05)^{[44]}$.

Beyond the use of vascular endothelial growth factor inhibitors and immune checkpoint inhibitors, a German group assessed the use of an adjuvant multi-peptide vaccine after metastasectomy. The vaccine was distributed to 19 patients after complete metastasectomy, and this group was compared with a separate contemporary cohort of 44 patients who underwent metastasectomy only. The vaccine was well-tolerated and demonstrated an improvement in overall survival (HR of death $=0.19, P=0.012$ ) compared to patients undergoing resection alone ${ }^{[45]}$.

\section{CURRENT ROLE OF METASTASECTOMY}

The evidence supporting the role of metastasectomy, historically, is mostly retrospective and observational. However, despite the limited prospective evidence, available studies suggest a benefit of complete resection in the properly selected patient ${ }^{[38]}$. A recent systematic review of 56 studies demonstrated that overall survival ranges from 36-142 months for those undergoing metastasectomy vs. 8-27 months for those subject to nonoperative management. Prognostic factors associated with overall survival included disease-free survival from time of nephrectomy, number of metastases, patient performance status, and primary tumor features, specifically grade, stage, presence of sarcomatoid features, and nodal status. The most important 
prognostic indicator was complete resection ${ }^{[36]}$.

As previously discussed, the use of pazopanib in the adjuvant setting failed to demonstrate an improvement in survival and, further, may have worsened outcomes in patients receiving the immunotherapy compared to placebo ${ }^{[4]}$. However, the combined role of metastasectomy and many immunotherapeutic agents remains unknown. One recent editorial proposed the possibility that metastasectomy may be useful in the setting of treatment beyond progression due to the intratumor heterogeneity of disease in $\mathrm{mRCC}^{[46]}$.

Investigators queried the Canadian Kidney Cancer information system database to review the records of 229 patients who underwent complete metastasectomy, matched with 803 patients who did not. Patients who did not undergo metastasectomy were more likely to receive targeted therapy in this cohort ( $74 \% v s .47 \%$ ). The 1 - and 5-year overall survival rates were $96 \%$ and $63 \%$ in the metastasectomy group, as compared to $90 \%$ and $51 \%$ in the group that did not undergo surgical resection, respectively. The effect of systemic therapy on these rates was not assessed. Risk of mortality was increased in patients who did not undergo metastasectomy $(\mathrm{HR}=0.41, P<0.001)$. Dragomir et al. ${ }^{[47]}$ noted that age $>65$ and the presence of brain metastases were factors associated with a worse prognosis.

Lyon et al. ${ }^{[48]}$ retrospectively assessed the role of complete metastasectomy in the post-cytokine era, including 586 patients who underwent primary treatment for renal cell carcinoma with subsequent development of metastatic disease between 2006 and 2017. One hundred-fifty-eight patients were treated with complete metastasectomy, $93 \%$ of which did not receive systemic therapy. The authors noted that cancer-specific survival was improved significantly amongst patients who underwent complete metastasectomy compared to patients who did not ( $84 \% v s .54 \%)$. In a multivariate analysis, the hazard ratio for death from mRCC was reduced significantly in patients who underwent complete metastasectomy (HR $=0.47, P<0.001)$, regardless of age, gender, timing, number, and location of metastases ${ }^{[48]}$.

In a retrospective review of 314 patients with mRCC, 98 patients underwent metastasectomy. Amongst these 98 patients, 45 patients underwent complete resection, while the remaining 53 were incompletely resected. The authors reported that metastasectomy status was an independent predictor of overall survival. The group further analyzed the survival for patients undergoing metastasectomy $v s$. no resection in the various systemic therapy eras. The Kaplan-Meier curve demonstrated similar results for metastasectomy in each era, including the early targeted therapy (2008-2011), late targeted therapy (2012-2016), and immunotherapy eras (2016-2018). However, the Kaplan-Meier curves for each systemic therapy demonstrated improving survival in each era, persistently inferior to survival demonstrated in patients undergoing metastasectomy ${ }^{[38]}$.

\section{ROLE OF SURGICAL MANAGEMENT IN THE ERA OF IMMUNOTHERAPY}

Given the rapidly evolving landscape of systemic therapy for mRCC, and the sparsity of high-quality studies specifically addressing the role of systematic therapy in patients undergoing metastasectomy, the role of surgical management should be considered more broadly.

The role of cytoreductive nephrectomy in early studies demonstrated a survival benefit in men concurrently treated with interferons ${ }^{[49,50]}$. In the targeted therapy era, the CARMENA trial randomized 450 intermediate and poor-risk patients to cytoreductive nephrectomy followed by sunitinib or sunitinib alone. In this study, the hazard ratio for death amongst patients receiving sunitinib-alone was 0.89 (95\%CI: 0.71-1.10), demonstrating noninferiority compared to patients undergoing nephrectomy followed by sunitinib. Overall survival was 13.9 and 18.4 months in patients in the nephrectomy-sunitinib and sunitinib cohorts, 
respectively ${ }^{[51]}$. However, a criticism of the CARMENA trial was the significant proportion of patients with poor performance status and poor-risk disease, which was subsequently associated with worse survival outcomes in a meta-analysis ${ }^{[52]}$.

The SURTIME trial randomized 99 patients to immediate cytoreductive nephrectomy with subsequent sunitinib therapy or sunitinib therapy followed by deferred cytoreductive nephrectomy. Both arms demonstrated similar progression-free survival while deferred cytoreductive nephrectomy was associated with improved overall survival (overall survival $\mathrm{HR}=0.57,95 \% \mathrm{CI}$ : $0.34-0.95, P=0.03$ ). Median overall survival was 15.0 and 32.4 months in the immediate and the deferred cytoreductive nephrectomy arms, respectively ${ }^{[53]}$. A subsequent systematic review concluded that upfront cytoreductive nephrectomy is not associated with survival benefit in patients with the intermediate and poor-risk disease. However, evidence in patients with good performance status and good or intermediate-risk disease suggest that intervention may be beneficial ${ }^{[54]}$, paralleling the findings of observational studies in the metastasectomy literature.

The introduction of immunotherapy proposed a new set of questions regarding the respective roles of systemic therapy and cytoreductive nephrectomy in the management of mRCC. A study randomizing 104 patients to receive three combinations of immune checkpoint inhibitors with subsequent cytoreductive nephrectomy and adjuvant nivolumab was noted to be safe, but survival outcomes were not assessed ${ }^{[55]}$.

A retrospective analysis of patients undergoing cytoreductive nephrectomy with neoadjuvant/adjuvant immunotherapy $v s$. immunotherapy-alone demonstrated improved overall survival amongst patients who underwent $\mathrm{CN}$ in combination with immunotherapy ( $\mathrm{HR}=0.23$, 95\%CI: $0.15-0.37, P<0.001$ ). In a subanalysis exploring differences in the timing of systemic therapy and $\mathrm{CN}$, those undergoing systemic therapy followed by $\mathrm{CN}(n=24)$ did not reach median overall survival, while median overall survival was 30 months for patients undergoing upfront $\mathrm{CN}(n=197)$. These findings were not significant, likely due to the small number of patients receiving neoadjuvant treatment ${ }^{[56]}$.

\section{PROSPECTIVE ROLE OF METASTASECTOMY IN THE ERA OF IMMUNOTHERAPY}

Review of the available literature suggests that one of the primary goals of metastasectomy should be complete resection, which is associated with significant survival benefits. However, evidence exploring the utility of metastasectomy in the era of immunotherapy has been limited to the use of immunotherapeutic agents in the adjuvant setting ${ }^{[4,45]}$. A recent animal study evaluating the timing of immunotherapy delivery strongly supports neoadjuvant, rather than adjuvant, use of these therapies ${ }^{[57]}$.

It is well-established that renal cell carcinoma exhibits significant intratumoral heterogeneity ${ }^{[58,59]}$. Further, these genomic differences have been associated with differences in therapeutic response to PD-L1 inhibitors ${ }^{[0]}$. These findings suggest that the use of neoadjuvant, therapy to decrease metastatic burden prior to metastasectomy may increase the likelihood of complete resection, thereby conferring a survival benefit in these patients. However, any associated effect may be modulated by the location, extensiveness, or genomics of these metastases ${ }^{[1]]}$.

PROSPER RCC is a phase III RCT, randomizing patients with clinical stage $\geq \mathrm{T} 2$, in a 1:1 fashion, to either surgery (partial or radical nephrectomy) alone or neoadjuvant PD-L1 blockade with nivolumab, followed by surgery and adjuvant nivolumab. The planned primary endpoint is 5-year recurrence-free survival. This trial may have significant implications on the treatment paradigm in the primary management of RCC and, pending findings, may also impact mRCC treatment strategies ${ }^{[62]}$. 


\section{CONCLUSION}

The role of metastasectomy in the era of immunotherapy remains underexplored and requires prospective study to be fully ascertained. Initial evidence suggests that adjuvant systemic therapy, including immunotherapy, may not improve outcomes. Nevertheless, the role of neoadjuvant systemic therapy has not been elucidated, nor have all contemporary treatment options been explored.

Historically, retrospective evidence has demonstrated that metastasectomy may be a valuable management option in the properly selected patient, dependent on factors related to (1) metastatic characteristics such as the site, number of organs involved and number of metastases per site; (2) primary tumor factors such as histologic grade, and stage; and (3) patient factors including age, and medical co-morbidities. Generally, complete resection of solitary, single-organ metastases, with favorable primary tumor histology, in patients with better performance status are associated with survival benefits after metastasectomy. Further, despite the evolving landscape of therapeutic agents, metastasectomy remains the only means of a definitive cure for mRCC. Nevertheless, it must be highlighted that a significant portion of the literature is retrospective in nature and, as such, is limited by associated biases.

The decision to pursue metastasectomy should be considered within the framework of a multi-disciplinary management discussion and, pending the results of future studies, may be a valuable tool in a multimodal treatment approach.

\section{DECLARATIONS}

\section{Authors' contributions}

Made substantial contributions to conception and design of the study and performed data analysis and interpretation: Feuer Z, Taylor J, Huang WC

Performed data acquisition, as well as provided administrative, technical, and material support: Feuer Z, Taylor J, Huang WC

\section{Availability of data and materials}

Not applicable.

\section{Financial support and sponsorship}

None.

\section{Conflicts of interest}

All authors declared that there are no conflicts of interest.

\section{Ethical approval and consent to participate}

Not applicable.

\section{Consent for publication}

Not applicable.

\section{Copyright}

(c) The Author(s) 2021.

\section{REFERENCES}

1. Siegel RL, Miller KD, Jemal A. Cancer statistics, 2020. CA Cancer J Clin 2020;70:7-30. DOI PubMed

2. Capitanio U, Montorsi F. Renal cancer. Lancet 2016;387:894-906. DOI PubMed

3. Motzer RJ, Jonasch E, Boyle S, et al. NCCN guidelines insights: kidney cancer, version 1.2021. J Natl Compr Canc Netw 2020;18:1160-70. DOI PubMed 
4. Zaid HB, Parker WP, Safdar NS, et al. Outcomes following complete surgical metastasectomy for patients with metastatic renal cell carcinoma: a systematic review and meta-analysis. J Urol 2017;197:44-9. DOI PubMed

5. Soares A, Monteiro FSM, Maluf FC, et al. Advanced renal cell carcinoma (RCC) management: an expert panel recommendation from the Latin American Cooperative Oncology Group (LACOG) and the Latin American Renal Cancer Group (LARCG). J Cancer Res Clin Oncol 2020;146:1829-45. DOI PubMed PMC

6. Kavolius JP, Mastorakos DP, Pavlovich C, Russo P, Burt ME, Brady MS. Resection of metastatic renal cell carcinoma. J Clin Oncol 1998;16:2261-6. DOI PubMed

7. der Poel HG, Roukema JA, Horenblas S, van Geel AN, Debruyne FM. Metastasectomy in renal cell carcinoma: a multicenter retrospective analysis. Eur Urol 1999;35:197-203. DOI PubMed

8. Alt AL, Boorjian SA, Lohse CM, Costello BA, Leibovich BC, Blute ML. Survival after complete surgical resection of multiple metastases from renal cell carcinoma. Cancer 2011;117:2873-82. DOI PubMed

9. Ng CS, Wood CG, Silverman PM, Tannir NM, Tamboli P, Sandler CM. Renal cell carcinoma: diagnosis, staging, and surveillance. AJR Am J Roentgenol 2008;191:1220-32. DOI PubMed

10. Vikram R, Beland MD, Blaufox MD, et al. ACR appropriateness criteria renal cell carcinoma staging. J Am Coll Radiol 2016;13:51825. DOI PubMed

11. Win AZ, Aparici CM. Clinical effectiveness of (18)f-fluorodeoxyglucose positron emission tomography/computed tomography in management of renal cell carcinoma: a single institution experience. World J Nucl Med 2015;14:36-40. DOI PubMed PMC

12. Verhoeff SR, van Es SC, Boon E, et al. Lesion detection by $\left[{ }^{89} \mathrm{Zr}\right] \mathrm{Zr}$-DFO-girentuximab and $\left[{ }^{18} \mathrm{~F}\right] \mathrm{FDG}-\mathrm{PET} / \mathrm{CT}$ in patients with newly diagnosed metastatic renal cell carcinoma. Eur J Nucl Med Mol Imaging 2019;46:1931-9. DOI

13. Pfannschmidt J, Hoffmann H, Muley T, Krysa S, Trainer C, Dienemann H. Prognostic factors for survival after pulmonary resection of metastatic renal cell carcinoma. Ann Thorac Surg 2002;74:1653-7. DOI PubMed

14. Bölükbas S, Kudelin N, Eberlein M, Fisseler-Eckhoff A, Schirren J. The influence of the primary tumor on the long-term results of pulmonary metastasectomy for metastatic renal cell carcinoma. Thorac Cardiovasc Surg 2012;60:390-7. DOI PubMed

15. Kudelin N, Bölükbas S, Eberlein M, Schirren J. Metastasectomy with standardized lymph node dissection for metastatic renal cell carcinoma: an 11-year single-center experience. Ann Thorac Surg 2013;96:265-70: discussion 270-1. DOI PubMed

16. Saricam M. Factors affecting long-term survival following pulmonary metastasectomy of renal cell carcinoma. Urol J 2020;17:492-6. DOI PubMed

17. Kume H, Kakutani S, Yamada Y, et al. Prognostic factors for renal cell carcinoma with bone metastasis: who are the long-term survivors? J Urol 2011;185:1611-4. DOI PubMed

18. Huang Z, Du Y, Zhang X, Liu H, Liu S, Xu T. Clear cell renal cell carcinoma bone metastasis: what should be considered in prognostic evaluation. Eur J Surg Oncol 2019;45:1246-52. DOI PubMed

19. Kollender Y, Bickels J, Price WM, et al. Metastatic renal cell carcinoma of bone: indications and technique of surgical intervention. $J$ Urol 2000;164:1505-8. PubMed

20. Higuchi T, Yamamoto N, Hayashi K, et al. Long-term patient survival after the surgical treatment of bone and soft-tissue metastases from renal cell carcinoma. Bone Joint J 2018;100-B:1241-8. DOI PubMed

21. Lin PP, Mirza AN, Lewis VO, et al. Patient survival after surgery for osseous metastases from renal cell carcinoma. J Bone Joint Surg Am 2007;89:1794-801. DOI PubMed

22. Ptashnikov D, Zaborovskii N, Kostrickii S, et al. Metastasectomy and targeted therapy for patients with spinal metastases of renal cell carcinoma. Int J Spine Surg 2020;14:982-8. DOI PubMed PMC

23. Amini A, Altoos B, Bourlon MT, et al. Local control rates of metastatic renal cell carcinoma (RCC) to the bone using stereotactic body radiation therapy: Is RCC truly radioresistant? Pract Radiat Oncol 2015;5:e589-96. DOI PubMed PMC

24. Jhaveri PM, Teh BS, Paulino AC, et al. A dose-response relationship for time to bone pain resolution after stereotactic body radiotherapy (SBRT) for renal cell carcinoma (RCC) bony metastases. Acta Oncol 2012;51:584-8. DOI PubMed

25. Martel G, Bertens KA, Canil C. Surgical management of genitourinary cancer liver metastases. Surg Oncol Clin N Am 2021;30:89102. DOI PubMed

26. Ruys AT, Tanis PJ, Nagtegaal ID, et al. Surgical treatment of renal cell cancer liver metastases: a population-based study. Ann Surg Oncol 2011;18:1932-8. DOI PubMed PMC

27. Staehler MD, Kruse J, Haseke N, et al. Liver resection for metastatic disease prolongs survival in renal cell carcinoma: 12-year results from a retrospective comparative analysis. World J Urol 2010;28:543-7. DOI PubMed

28. Joyce DD, Psutka SP, Groeschl RT, et al. Complications and outcomes associated with surgical management of renal cell carcinoma involving the liver: a matched cohort study. Urology 2017;99:155-61. DOI PubMed

29. Wroński M, Arbit E, Russo P, Galicich JH. Surgical resection of brain metastases from renal cell carcinoma in 50 patients. Urology 1996;47:187-93. DOI PubMed

30. Capitanio U, Becker F, Blute ML, et al. Lymph node dissection in renal cell carcinoma. Eur Urol 2011;60:1212-20. DOI PubMed

31. Blom JH, van Poppel H, Maréchal JM, et al; EORTC Genitourinary Tract Cancer Group. Radical nephrectomy with and without lymph-node dissection: final results of European Organization for Research and Treatment of Cancer (EORTC) randomized phase 3 trial 30881. Eur Urol 2009;55:28-34. DOI PubMed

32. Pantuck AJ, Zisman A, Dorey F, et al. Renal cell carcinoma with retroperitoneal lymph nodes: role of lymph node dissection. $J$ Urol 2003;169:2076-83. DOI PubMed

33. Feuerstein MA, Kent M, Bernstein M, Russo P. Lymph node dissection during cytoreductive nephrectomy: a retrospective analysis. Int J Urol 2014;21:874-9. DOI PubMed PMC 
34. Gershman B, Thompson RH, Moreira DM, et al. Radical nephrectomy with or without lymph node dissection for nonmetastatic renal cell carcinoma: a propensity score-based analysis. Eur Urol 2017;71:560-7. DOI PubMed

35. John NT, Blum KA, Hakimi AA. Role of lymph node dissection in renal cell cancer. Urol Oncol 2019;37:187-92. DOI PubMed

36. Ouzaid I, Capitanio U, Staehler M, et al; Young Academic Urologists Kidney Cancer Working Group of the European Association of Urology. Surgical metastasectomy in renal cell carcinoma: a systematic review. Eur Urol Oncol 2019;2:141-9. DOI PubMed

37. Ishihara H, Takagi T, Kondo T, et al. Prognostic impact of metastasectomy in renal cell carcinoma in the postcytokine therapy era. Urol Oncol 2021;39:77.e17-25. DOI PubMed

38. Takagi T, Fukuda H, Ishihara H, et al. Predictive factors for recurrence after complete metastasectomy in patients with metastatic renal cell carcinoma in the targeted therapy era. Urol Oncol 2020;38:515-20. DOI PubMed

39. Palumbo C, Pecoraro A, Knipper S, et al. Survival and complication rates of metastasectomy in patients with metastatic renal cell carcinoma treated exclusively with targeted therapy: a combined population-based analysis. Anticancer Res 2019;39:4357-61. DOI PubMed

40. Meyer CP, Sun M, Karam JA, et al. Complications after metastasectomy for renal cell carcinoma-a population-based assessment. Eur Urol 2017;72:171-4. DOI PubMed

41. Karam JA, Rini BI, Varella L, et al. Metastasectomy after targeted therapy in patients with advanced renal cell carcinoma. J Urol 2011;185:439-44. DOI PubMed PMC

42. Li JR, Ou YC, Yang CK, et al. The impact of local intervention combined with targeted therapy on metastatic renal cell carcinoma. Anticancer Res 2018;38:5339-45. DOI PubMed

43. Procopio G, Apollonio G, Cognetti F, et al. Sorafenib versus observation following radical metastasectomy for clear-cell renal cell carcinoma: results from the phase 2 randomized open-label RESORT study. Eur Urol Oncol 2019;2:699-707. DOI PubMed

44. Appleman LJ, Puligandla M, Pal SK, et al. Randomized, double-blind phase III study of pazopanib versus placebo in patients with metastatic renal cell carcinoma who have no evidence of disease following metastasectomy: a trial of the ECOG-ACRIN cancer research group (E2810). J Clin Oncol 2019;37:4502. DOI

45. Rausch S, Gouttefangeas C, Hennenlotter J, et al. Results of a phase $1 / 2$ study in metastatic renal cell carcinoma patients treated with a patient-specific adjuvant multi-peptide vaccine after resection of metastases. Eur Urol Focus 2019;5:604-7. DOI PubMed

46. Ishihara H, Takagi T, Kondo T, Fukuda H, Yoshida K, Tanabe K. Nivolumab treatment beyond progression for metastatic renal cell carcinoma: New role of metastasectomy in the immune checkpoint inhibitor era? Int J Urol 2020;27:691-2. DOI PubMed

47. Dragomir A, Nazha S, Wood LA, et al. Outcomes of complete metastasectomy in metastatic renal cell carcinoma patients: The Canadian Kidney Cancer information system experience. Urol Oncol 2020;38:799.e1-799.e10. DOI PubMed

48. Lyon TD, Thompson RH, Shah PH, et al. Complete surgical metastasectomy of renal cell carcinoma in the post-cytokine era. $J$ Urol 2020;203:275-82. DOI PubMed

49. Flanigan RC, Salmon SE, Blumenstein BA, et al. Nephrectomy followed by interferon alfa- $2 \mathrm{~b}$ compared with interferon alfa- $2 \mathrm{~b}$ alone for metastatic renal-cell cancer. N Engl J Med 2001;345:1655-9. DOI PubMed

50. Mickisch G, Garin A, van Poppel H, de Prijck L, Sylvester R. Radical nephrectomy plus interferon-alfa-based immunotherapy compared with interferon alfa alone in metastatic renal-cell carcinoma: a randomised trial. Lancet 2001;358:966-70. DOI PubMed

51. Méjean A, Ravaud A, Thezenas S, et al. Sunitinib alone or after nephrectomy in metastatic renal-cell carcinoma. $N$ Engl J Med 2018;379:417-27. DOI PubMed

52. Massari F, Di Nunno V, Gatto L, et al. Should CARMENA really change our attitude towards cytoreductive nephrectomy in metastatic renal cell carcinoma? Target Oncol 2018;13:705-14. DOI PubMed

53. Bex A, Mulders P, Jewett M, et al. Comparison of immediate vs deferred cytoreductive nephrectomy in patients with synchronous metastatic renal cell carcinoma receiving sunitinib: the SURTIME randomized clinical trial. JAMA Oncol 2019;5:164-70. DOI PubMed PMC

54. Bhindi B, Abel EJ, Albiges L, et al. Systematic review of the role of cytoreductive nephrectomy in the targeted therapy era and beyond: an individualized approach to metastatic renal cell carcinoma. Eur Urol 2019;75:111-28. DOI PubMed

55. Gao J, Karam JA, Tannir NM, et al. A pilot randomized study evaluating nivolumab (nivo) or nivo + bevacizumab (bev) or nivo + ipilimumab (ipi) in patients with metastatic renal cell carcinoma (MRCC) eligible for cytoreductive nephrectomy $(\mathrm{CN})$, metastasectomy (MS) or posttreatment biopsy (Bx). J Clin Oncol 2018;36:4520. DOI

56. Singla N, Hutchinson RC, Ghandour RA, et al. Improved survival after cytoreductive nephrectomy for metastatic renal cell carcinoma in the contemporary immunotherapy era: An analysis of the National Cancer Database. Urol Oncol 2020;38:604.e9-604.e17. DOI PubMed PMC

57. Liu J, Blake SJ, Yong MC, et al. Improved efficacy of neoadjuvant compared to adjuvant immunotherapy to eradicate metastatic disease. Cancer Discov 2016;6:1382-99. DOI PubMed

58. Clark DJ, Dhanasekaran SM, Petralia F, et al; Clinical Proteomic Tumor Analysis Consortium. Integrated proteogenomic characterization of clear cell renal cell carcinoma. Cell 2020;180:207. DOI PubMed

59. Ricketts CJ, Linehan WM. Intratumoral heterogeneity in kidney cancer. Nat Genet 2014;46:214-5. DOI PubMed PMC

60. Miao D, Margolis CA, Gao W, et al. Genomic correlates of response to immune checkpoint therapies in clear cell renal cell carcinoma. Science 2018;359:801-6. DOI PubMed PMC

61. Verbiest A, Couchy G, Job S, et al. Molecular subtypes of clear-cell renal cell carcinoma are prognostic for outcome after complete metastasectomy. Eur Urol 2018;74:474-80. DOI PubMed

62. Patel HD, Puligandla M, Shuch BM, et al. The future of perioperative therapy in advanced renal cell carcinoma: how can we PROSPER? Future Oncol 2019;15:1683-95. DOI PubMed PMC 